\title{
Additive main effects and multiplicative interaction analysis of European linseed (Linum Ustatissimum L.) cultivars under South African conditions
}

\begin{abstract}
Flax (Linum ustatissimum L.) is a multipurpose crop cultivated for both the fibre in the stem (fibre flax) or for its oil pressed from the seed (linseed). The natural qualities of flax make it a desirable commodity for manufacturers seeking alternative solutions to chemical and plastic-based products. As there is no production of flax in South Africa, ten linseed cultivars were imported from the Netherlands and the United Kingdom and evaluated for their adaptability under South African conditions. These cultivars were planted during the 2005 to 2009 season at six different localities (environments) in the Western Cape Province under rain fed conditions. The localities were, Bredasdorp, Caledon, Elsenburg, Koringberg, Langgewens and Napier. The Additive Main Effects and Multiplicative Interaction (AMMI) statistical method as well as the PCA (Principal Component Analysis) model were used to describe cultivar environment interaction on grain yield. Results indicated that the cultivars Sunrise, Capricorn, Bilstar, Virgo and Taurus were the most adapted cultivars for high potential environments.
\end{abstract}

Keywords: flax, AMMI model, ASV, linseed
Volume 2 Issue 3 - 2015

\section{MJ Jacobsz, WJC van der Merwe, MM van der Westhuizen}

Agricultural Research Council - Institute for Industrial Crops, South Africa Correspondence: MJ Jacobsz, Agricultural Research Council -
Institute for Industrial Crops, South Africa, Email mjacobszl@telkomsa.net

Received: April 17,2015 | Published: April 27, 2015
Abbreviations: AMMI, additive main effects and multiplicative interaction; ASV, ammi stability value; PCA, principal component analysis; $\mathrm{CxE}$, cultivar $\mathrm{x}$ environment interaction

\section{Introduction}

Flax (Linum ustatissimum L.) is a multipurpose crop cultivated for both the fibre in the stem (fibre flax) or for its oil pressed from the seed (linseed). The natural qualities of flax make it a desirable commodity for manufacturers seeking alternative solutions to chemical and plastic-based products. Linseed grains, which are either brown or yellow, contain $35-45 \%$ oil and $18-26 \%$ protein. Linseed oil is the most widely available botanical source of Omega-3 fatty acids. Alphalinolenic acid (ALA) is the important Omega-3 fatty acid in linseed, which is of considerable benefit to humans and animals. Linseed cultivars vary in their ALA content, from cultivars with an ALA content of $2 \%$, which makes them unsuitable for the Omega-3 market, to ALA-rich cultivars $(60 \%$ ALA) which are extremely suitable for the Omega-3 human food and animal feed markets. Cultivars with an ALA content of $2 \%$ compete with sunflowers for processing into margarine and cooking oil. ${ }^{1}$

Practically, all linseed and linseed products used in South Africa are currently being imported from countries such as Canada, Germany, Denmark and the Netherlands. Canada is the world's leading producer of linseed oil and according to Statistics Canada the current production is running $13 \%$ below demand. ${ }^{2}$ Thus, here is a high demand for this commodity which can potentially be exploited by local farmers. Linseed is an excellent rotational crop with wheat and barley. Flax has great potential to be planted commercially under South African conditions. ${ }^{3}$ The current study was undertaken to interpret Cultivar $x$ Environment (CE) interaction obtained by AMMI analysis of yield performance of 10 linseed cultivars over 6 environments, to visually assess how yield performances vary across environments on a biplot and to group the cultivars having similar response patterns across varying environments together.

\section{Materials and methods}

\section{Description of the study area}

Five linseed cultivars (Bilton, Biltstar, Capricorn, Taurus and Virgo -imported from the Netherlands) and another five cultivars imported from the UK (Gemini, Laser, Linus, Marmalade and Sunrise) were evaluated over a four year period from 2005 to 2009 at six localities (environments) namely Bredasdorp, Caledon, Elsenburg, Koringberg, Langgewens \& Napier in the Western Cape Province of South Africa. The trails were planted from mid-May to early June after the first rains and cultivated under rain fed conditions. A seeding rate of $50 \mathrm{~kg}$ seed $\mathrm{ha}^{-1}$ was used. Standard fertilization and weed control practices were implemented throughout the study. $400 \mathrm{~kg}$ $\mathrm{ha}^{-1}$ of 2:3:4 (27) was incorporated in the soil before planting. Two top dressings of $50 \mathrm{~kg} \mathrm{ha}^{-1}$ was done with Limestone ammonium nitrate (LAN). Harvesting of grain was commenced during November. The trial design was a randomized block design with three replications. Plot size was $1 \mathrm{mx} 4 \mathrm{~m}$ with 6 rows. The inter-row spacing was $25 \mathrm{~cm}$ with a sowing depth of $2 \mathrm{~cm}$. Linseed grain yield data was used to evaluate the different cultivars and localities applying the Additive Main effects and Multiplicative Interaction (AMMI) model. ${ }^{4}$ AMMI stability values (ASV) were computed from stability values as derived by Purchase et al. ${ }^{5}$

\section{Results and discussion}

Although numerous statistical techniques are available to describe cultivar $\mathrm{x}$ environment interaction ${ }^{6-8}$ the additive main effects and multiplicative interaction method (AMMI) has been used by various researchers on crops such as bread wheat, ${ }^{5}$ cotton, ${ }^{9}$ durum wheat, ${ }^{10}$ faba bean, ${ }^{11}$ lucern, ${ }^{12}$ maize, ${ }^{13}$ potatoes ${ }^{14}$ and tobacco. ${ }^{15}$ The graphical 
version (biplot) of the cultivar means and the first interaction (PCA) Principle component analysis scores eases interpretation and identification of high yielding cultivars. Principal component analysis is a variable reduction procedure and is the most frequently used multivariate method. ${ }^{6,16}$ Its aim is to transform the data from one set of coordinate axes to another, which preserves, as much as possible, the original configuration of the set of points and concentrates most of the data structure in the first principal component axis.

From the ANOVA table for AMMI analysis it can be seen that the mean squares for cultivars, environments and $\mathrm{C} x \mathrm{E}$ interaction were found to be highly significant (Table 1). This suggested that a broad range of diversity existed among cultivars and among environments and that the performance of the cultivars was inconsistent over environments. Of the total treatment variation, the variance due to difference in the environment was the largest $(61.2 \%)$ as can be expected in diverse production areas in the Cape Province of South Africa. This was followed by the variance due to $\mathrm{C} x \mathrm{E}$ interactions $(16.7 \%)$ (Table 2). In contrast, the variance due to cultivar was only $2.0 \%$. The ordinary ANOVA model accounted for $63.2 \%$ of the trial sum of squares, concentrating only on the cultivar effects and environment effects. Although it is obvious that cultivars, environments and cultivar $\mathrm{x}$ environment interaction exerted a significant effect on yield, it is not clear which cultivars, environments or cultivar $\mathrm{x}$ environment interactions were responsible for the differences, or how these responses differ. The ANOVA model was thus found not to be adequate enough for analyzing the linseed grain yield data, as $\mathrm{C} \times \mathrm{E}$ interactions were highly significant. The ANOVA model was, therefore, combined with PCA (Principal Component Analysis) model to further analyze the residuals of the ANOVA model, which contains the $\mathrm{C} \times \mathrm{E}$ interaction (Table 1). Results from the analysis of multiplicative effects showed that the first interaction principal component analysis (IPCA1) captured $54.7 \%$ of the interaction sum of squares. The second interaction principal component analysis (IPAC2) explained only $13.3 \%$ of the $\mathrm{C} \times \mathrm{E}$ interaction. This is of relative minor magnitude and it would be difficult to draw meaningful conclusions from this principal component factor. Further analysis would, therefore, mostly concentrate on the IPCA1 scores.

The IPCA1 scores and mean performances data (grain yield) for both cultivar and environment that were used to construct an AMMI biplot are presented in Table 3. This was used to identify a specific pattern of the main effect and $\mathrm{C} x \mathrm{E}$ interactions on both the cultivars and environments simultaneously. ${ }^{6-8}$ It is clear from the biplot that the points for environment were more scattered than the points for cultivars (Figure 1). This indicated that variability due to environments was higher than that of cultivar differences. According to the AMMI model, cultivars which are characterized by means greater than grand mean and the IPCA score nearly zero are considered as generally adaptable to all environments (this suggests negligible or no $\mathrm{C}$ x E interaction). The cultivars, Laser and Linus meet these requirements. On the other hand, cultivars with high mean performance and with large value of IPCA scores are considered as having specific adaptability to the environments. The cultivars Sunrise, Capricorn, Bilstar, Virgo and Taurus fell into this category. Favourable environments for these cultivars can be characterized as with high mean and large IPCA score with same sign as of cultivar IPCA1 score. The environments in quadrant II of the biplot, i.e. Elsenburg 2007, Caledon 2007, Langgewens 2007; 2009 and Napier 2008 , will thus be suitable environments for these cultivars. Similar sign of IPCA1 scores implies positive interaction and as a result will suggest higher yield of related cultivars. Lower potential environments predominating in quadrant I nemely Langgewens 2006, Bredasdorp 2006 and Koringberg 2006 and 2008 are grouped together, because of the low rainfall received.

AMMI analysis generates predicted means which gave greater accuracy, hence greater value for making selections than do the unadjusted or observed means. ${ }^{4}$ The observed and AMMI predicted values are demonstrated in Table 2. Based on this predicted yield data, it is evident that Virgo is one of the first five AMMI selections in 16 out of 20 environments, Linus 13 out of 20, Sunrise is 12 out of 20 and Taurus 11 out of 20 environments, but no clear pattern is evident in terms of localities or seasons (Table 3 ).

Purchase et al., 5 developed a test based on AMMI model's IPCA1 and IPCA2 values for each cultivar and each environment. ${ }^{5}$ It is called the AMMI Stability Value (ASV). An AMMI stability value is the distance from the coordinate point to the origin in a two dimensional scatter gram of ICPA1 scores against ICPA2 scores.). Cultivar Bilton (with the lowest ASV), was ranked as the most stable cultivar but it had a below average yield performance, except for the highest yield at Elsenburg (2006). The environment Napier in the 2007 season was the most stable environment and Langgewens 2008 and Elsenburg 2008 was the least stable environments. The latter two environments received flush floods during the 2008 season which had an effect on the grain yield. Cultivar Bilton was ranked with the lowest ASV, as the most stable cultivar but it had a below average yield performance.

Table I ANOVA for AMMI model for the cultivar evaluation trials at the different localities in the Western Cape Province over the period 2005 - 2009

\begin{tabular}{|c|c|c|c|c|}
\hline Source & df & SS & MS & Prob \\
\hline Block & 40 & 19175697 & 479392 & $<0.001$ \\
\hline Cultivar & 9 & 3517968 & 390885 & $<0.001$ \\
\hline C x E Interaction & $|7|$ & 29286665 & $|7| 267$ & $<0.001$ \\
\hline ICPA2 & 25 & 3901523 & $15606 \mid$ & $<0.001$ \\
\hline Residual & 119 & 9336479 & 78456 & $<0.001$ \\
\hline Error & 360 & 16098679 & 44719 & \\
\hline Total & 599 & 175578894 & 293117 & \\
\hline
\end{tabular}


Table 2 AMMI selections per environment

\begin{tabular}{|c|c|c|c|c|c|c|c|c|}
\hline \multirow{2}{*}{$\begin{array}{l}\text { Environment } \\
\text { Elsenburg }\end{array}$} & \multirow{2}{*}{$\begin{array}{l}\text { Year } \\
2007\end{array}$} & \multirow{2}{*}{$\begin{array}{l}\text { Mean } \\
1349\end{array}$} & \multirow{2}{*}{$\begin{array}{l}\text { IPCA I } \\
\text { Score } \\
15.2\end{array}$} & \multicolumn{2}{|c|}{ AMMI Selection } & \multirow[b]{2}{*}{ Gemini } & \multirow[b]{2}{*}{ Laser } & \multirow[b]{2}{*}{ Bilton } \\
\hline & & & & Linus & Sunrise & & & \\
\hline Caledon & 2007 & 1280 & II.I & Sunrise & Marmalade & Taurus & Gemini & Capricorn \\
\hline Langgewens & 2007 & 1280 & 9.3 & Sunrise & Linus & Laser & Marmalade & Gemini \\
\hline Langgewens & 2006 & 488 & 5.7 & Sunrise & Laser & Linus & Marmalade & Virgo \\
\hline Koringberg & 2007 & 567 & 5.4 & Sunrise & Laser & Marmalade & Linus & Taurus \\
\hline Elsenburg & 2006 & 1953 & 5.1 & Linus & Sunrise & Laser & Biltstar & Virgo \\
\hline Elsenburg & 2009 & 1286 & 5.1 & Sunrise & Linus & Laser & Virgo & Marmalade \\
\hline Bredasdorp & 2006 & 574 & 4.8 & Sunrise & Linus & Laser & Virgo & Marmalade \\
\hline Caledon & 2006 & 1074 & 4.5 & Linus & Sunrise & Laser & Virgo & Biltstar \\
\hline Caledon & 2009 & 1449 & 4.5 & Sunrise & Laser & Linus & Virgo & Taurus \\
\hline Koringberg & 2008 & 831 & 3.2 & Linus & Biltstar & Virgo & Laser & Sunrise \\
\hline Koringberg & 2006 & 471 & 3.1 & Sunrise & Taurus & Virgo & Laser & Linus \\
\hline Napier & 2006 & 905 & 0.8 & Biltstar & Virgo & Linus & Laser & Taurus \\
\hline Napier & 2007 & 1017 & 0.3 & Taurus & Sunrise & Virgo & Capricorn & Marmalade \\
\hline Caledon & 2008 & 1862 & -1.5 & Biltstar & Virgo & Linus & Bilton & Laser \\
\hline Bredasdorp & 2007 & 477 & -1.9 & Taurus & Virgo & Capricorn & Biltstar & Laser \\
\hline Langgewens & 2009 & 1134 & -9.1 & Taurus & Virgo & Biltstar & Capricorn & Laser \\
\hline Napier & 2008 & 1460 & -11.5 & Taurus & Virgo & Biltstar & Capricorn & Laser \\
\hline Elsenburg & 2008 & 1211 & -26.9 & Taurus & Virgo & Biltstar & Capricorn & Laser \\
\hline Langgewens & 2008 & 967 & -26.9 & Taurus & Virgo & Capricorn & Biltstar & Laser \\
\hline
\end{tabular}

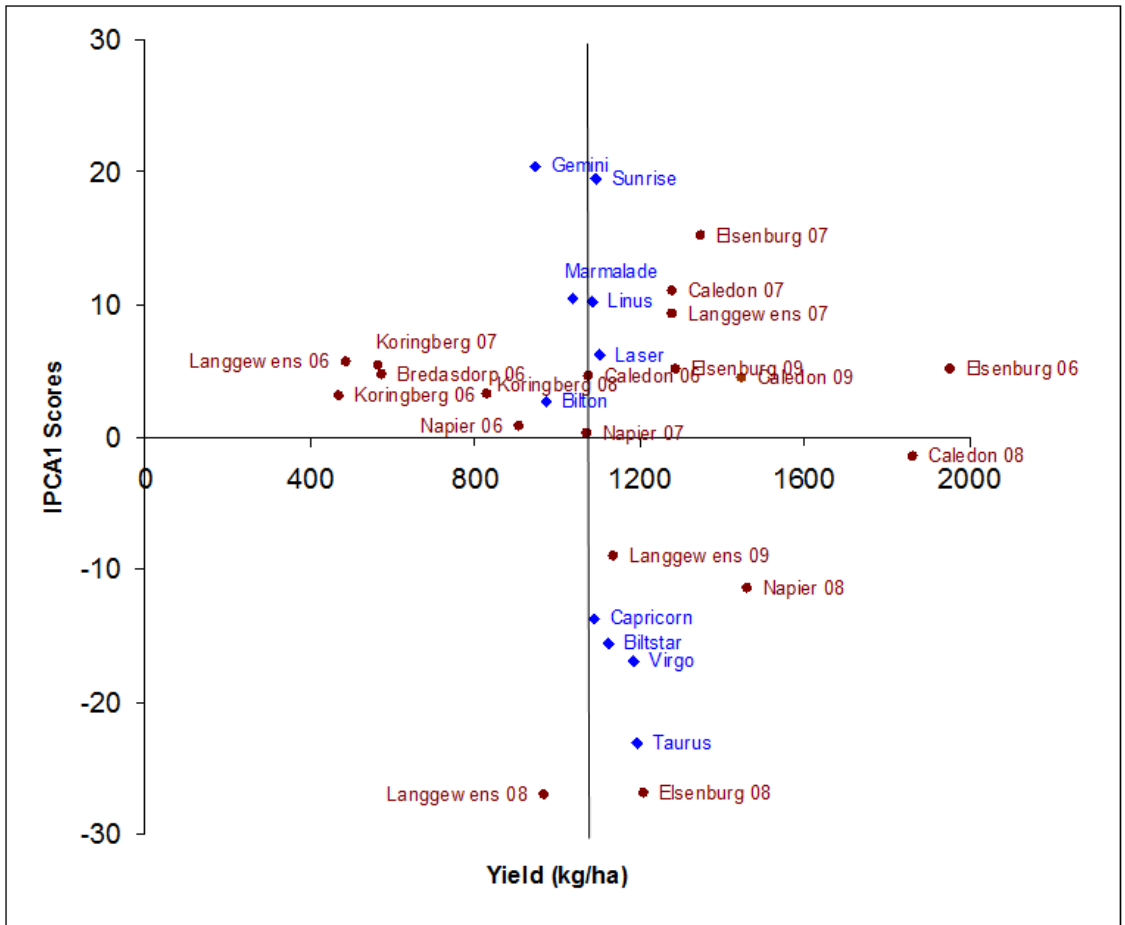

Figure I AMMI model biplot for linseed grain yield showing main and interaction effects for both cultivars and environments. 
Table 3 Observed and predicted grain yield $\left(\mathrm{kg}^{-1} \mathrm{ha}^{-1}\right)$ of 10 linseed cultivars evaluated over 6 localities from 2005-2009

\begin{tabular}{|c|c|c|c|c|c|c|c|c|c|c|c|c|}
\hline Environment & Year & $\begin{array}{l}\text { Yield } \\
\text { type }\end{array}$ & Bilton & Bilstar & rCapricorn & Gemini & Laser & Linus & Marmalade & Sunrise & Taurus & Virgo \\
\hline \multirow{2}{*}{ Bredasdorp } & \multirow{2}{*}{2006} & $\mathrm{~T}$ & 584 & 643 & 591 & $*$ & 546 & 569 & 493 & 702 & 694 & 528 \\
\hline & & AMMI & 495 & 562 & 501 & 530 & 625 & 636 & 569 & 668 & 560 & 597 \\
\hline \multirow{2}{*}{ Bredasdorp } & \multirow{2}{*}{2007} & $\mathrm{~T}$ & 324 & 482 & 427 & 382 & 614 & 455 & 391 & 453 & 747 & 594 \\
\hline & & AMMI & 334 & 523 & 526 & 303 & 478 & 442 & 428 & 467 & 655 & 610 \\
\hline \multirow{2}{*}{ Caledon } & \multirow{2}{*}{2006} & $\mathrm{~T}$ & 1009 & 1022 & 1062 & $*$ & 1255 & 988 & 1153 & 1070 & 983 & 1105 \\
\hline & & AMMI & 1020 & 1091 & 988 & 1022 & 1128 & 1149 & 1052 & 1148 & 1044 & 1102 \\
\hline \multirow{2}{*}{ Caledon } & \multirow{2}{*}{2007} & $\mathrm{~T}$ & 742 & 748 & 1420 & 1622 & $|76|$ & 1098 & $166 \mid$ & 1580 & 1509 & 1122 \\
\hline & & AMMI & 767 & 719 & $14 \mid 5$ & 1437 & 1304 & 1133 & 1604 & 1764 & 1483 & 1169 \\
\hline \multirow{2}{*}{ Caledon } & \multirow{2}{*}{2008} & $\mathrm{~T}$ & 2012 & 2184 & 1675 & 1792 & 1919 & 1824 & 1836 & 1552 & 1892 & 1933 \\
\hline & & AMMI & 1957 & 2138 & 1749 & 1660 & $190 \mid$ & 1975 & 1679 & 1720 & 1838 & 2001 \\
\hline \multirow{2}{*}{ Caledon } & \multirow{2}{*}{2009} & $\mathrm{~T}$ & 1293 & 1376 & 1348 & $14 \mid 4$ & 1367 & 1638 & $|44|$ & 1568 & 1500 & $|53|$ \\
\hline & & AMMI & 1344 & 1416 & 1397 & 1404 & 1494 & 1493 & 1456 & 1552 & 1462 & 1475 \\
\hline \multirow{2}{*}{ Napier } & \multirow{2}{*}{2007} & $\mathrm{~T}$ & 855 & 1066 & 873 & 856 & 993 & 938 & 903 & 763 & 880 & 992 \\
\hline & & AMMI & 887 & 1027 & 893 & 768 & 940 & 970 & 815 & 878 & 924 & 998 \\
\hline \multirow{2}{*}{ Napier } & \multirow{2}{*}{2008} & $\mathrm{~T}$ & 1005 & 819 & 990 & 447 & 1014 & 929 & 1166 & 1388 & 1237 & $1 \mid 48$ \\
\hline & & AMMI & 783 & 932 & 1098 & 905 & 1019 & 947 & 1048 & 1108 & 1220 & 1106 \\
\hline \multirow{2}{*}{ Napier } & \multirow{2}{*}{2009} & $\mathrm{~T}$ & 1052 & 1906 & 1510 & 1820 & 1328 & 1576 & |38| & |38| & 1823 & 1812 \\
\hline & & AMMI & 1366 & 1730 & 1592 & 1080 & $|4| 4$ & 1373 & 1268 & 1220 & 1799 & 1760 \\
\hline \multirow{2}{*}{ Elsenburg } & \multirow{2}{*}{2006} & $\mathrm{~T}$ & 2368 & 1566 & 1804 & 1594 & 1929 & 2098 & 2096 & 2077 & 1845 & 2047 \\
\hline & & AMMI & 1930 & 1991 & 1840 & 1907 & 2014 & 2052 & 1919 & 2020 & 1887 & 1973 \\
\hline \multirow{2}{*}{ Elsenburg } & \multirow{2}{*}{2007} & $\mathrm{~T}$ & 1374 & 1226 & 912 & 1746 & $|58|$ & 1643 & 1191 & 1433 & 1163 & 1227 \\
\hline & & AMMI & $|43|$ & 1306 & 1045 & 1498 & 1484 & 1599 & 1375 & 1568 & 985 & $120 \mid$ \\
\hline Flsenburg & & $\mathrm{T}$ & 1173 & 1713 & 1570 & 586 & 1146 & 626 & 942 & 701 & 2003 & 1655 \\
\hline Elsenburg & 2008 & AMMI & 1010 & 1656 & 1600 & 526 & 1059 & 926 & 896 & 709 & 1962 & 1770 \\
\hline & 2009 & $\mathrm{~T}$ & 1215 & 1578 & 1537 & 1234 & 1395 & 1298 & $105 \mid$ & 1564 & 1235 & 1740 \\
\hline Elsenburg & 2009 & AMMI & 1212 & 1273 & 1205 & 1247 & 1339 & 1354 & $|28|$ & 1382 & 1260 & 1303 \\
\hline & & $\mathrm{T}$ & 518 & 47I & 437 & 241 & 516 & 461 & 511 & 823 & 540 & 388 \\
\hline Korıngberg & 2006 & AMMI & 334 & 432 & 457 & 401 & 503 & 486 & 480 & 564 & 539 & 519 \\
\hline Koringberg & 2007 & $\mathrm{~T}$ & 388 & 631 & 562 & 630 & 641 & 374 & 491 & 855 & 488 & 616 \\
\hline KoringDerg & 2001 & AMMI & 429 & 484 & 526 & 546 & 613 & 598 & 604 & 710 & 588 & 575 \\
\hline & & $\mathrm{T}$ & 863 & 1057 & 808 & 808 & 810 & 848 & 750 & 858 & 783 & 690 \\
\hline Koringberg & 2009 & AMMI & 832 & 928 & 725 & 742 & 884 & 928 & 760 & 844 & 786 & 885 \\
\hline & & $\mathrm{T}$ & 313 & 494 & 508 & 541 & 488 & 457 & 478 & 623 & 491 & 413 \\
\hline Langgewens & 2006 & AMMI & 376 & 426 & 424 & 469 & 539 & 438 & 513 & 620 & 479 & 492 \\
\hline Langgewens & 2007 & $\mathrm{~T}$ & 1192 & 1095 & 1276 & 1575 & 1216 & 1500 & 1368 & 1194 & 1197 & 1200 \\
\hline Langgewens & 2001 & AMMI & 1186 & 1172 & 1163 & $|33|$ & 1354 & $137 \mid$ & 1337 & 1476 & II84 & 1225 \\
\hline & & $\mathrm{T}$ & 626 & 1258 & 1449 & 556 & 677 & 823 & 464 & 401 & 1843 & 1578 \\
\hline Langgewens & 2008 & AMMI & 698 & 1345 & 1400 & 292 & 805 & 641 & 692 & 505 & 1773 & 1523 \\
\hline Langgewens & 2009 & $\mathrm{~T}$ & 1043 & 1132 & 1350 & 481 & 1246 & 1203 & 1345 & 768 & 1260 & 1505 \\
\hline Langgewens & 2007 & AMMI & 1012 & 1332 & 1255 & 808 & 987 & 1098 & 1051 & 961 & 1444 & |39| \\
\hline
\end{tabular}

T - Observed mean yield AMMI - AMMI predicted yield *Cultivar not planted at locality 
Table 4 AMMI stability values for each cultivar

\begin{tabular}{lllll}
\hline Cultivar & Yield & IPCA I & IPCA 2 & ASV \\
\hline Bilton & 970 & 2.7 & 16.5 & 19.9 \\
Laser & 1100 & 6.2 & 2.4 & 25.7 \\
Linus & 1083 & 10.2 & 9.9 & 73.3 \\
Marmalade & 1038 & 10.5 & -9.7 & 44.0 \\
Capricorn & 1087 & -13.8 & -10.8 & 57.7 \\
Biltstar & 1124 & -15.6 & 16.5 & 66.1 \\
Virgo & 1184 & -16.9 & 0.9 & 69.9 \\
Sunrise & 1094 & 19.5 & -9.8 & 80.7 \\
Gemini & 944 & 20.4 & -2.7 & 84.0 \\
Taurus & 1194 & -23.2 & -13.3 & 96.3 \\
\hline
\end{tabular}

\section{Conclusion}

Cultivar Bilton gave the highest yield of $2368 \mathrm{~kg} \mathrm{ha}^{-1}$ at Elsenburg during the 2006 season. Bilton also gave the second highest yield at Caledon (2008) and Koringberg 2009, and the third best yield at Koringberg 2006. Cultivars Bilton and Laser were the AMMI best choices for most of the environments. Although Bilton had a slightly lower yield $\left(970 \mathrm{kgha}^{-1}\right)$ it had higher stability (ASV=19.9). Laser gave higher yields $(1100 \mathrm{~kg})$ but lower stability (ASV=25.7). Other high yield performers was the cultivar Sunrise that gave the highest yields in 5 out of the 20 environments namely Bredasdorp (2006), Napier (2008), Koringberg (2006+2007), and Langewens 2008 . Cultivar Bilstar gave the highest yield in 4 out of the 20 environments, namely: Caledon (2008), Napier $(2007+2009)$ and Koringberg (2009). Although Taurus was found to be the most unstable cultivar according to the ASV values, and showed limited adaptation to testing environments, it gave a grain yield that is above average (Table 4), whereas the most stable cultivar (Bilton) gave below average yields. For this reason, stability in itself cannot be used as the only parameter for selection, as the most stable cultivar wouldn't necessarily give the best yield performance. This contradiction was also found by cotton researchers in California ${ }^{17}$ that found a positive correlation between yield and stability and an association that suggests that cotton cultivars producing higher yields are, in general, lower in stability.

\section{Acknowledgements}

Department of Agriculture, Forestry and Fisheries for funding.

\section{Conflict of interest}

The author declares no conflict of interest.

\section{References}

1. Turner J. Linseed Law A handbook for growers and adviser. United Kingdom Ltd, Hadleigh, Suffolk: BASF; 1987.

2. www.statcan.gc.ca

3. Van Tonder CSM, Jansen A, Jacobsz M, et al. Adaptability of European fibre and linseed flax (Linum usitatissimum) cultivars to South African conditions. African Crop Science Conference Proceedings. 2003;6:38-41.

4. Gauch HG, Zobel RW. Accuracy and selection success in yield trial analysis. Theor Appl Genet. 1989;77(4):473-481.
5. Purchase JL, Hatting H, van Deventer CS. Genotype $x$ environment interaction of winter wheat (Triticum aestivum L.) in South Africa: II. Stability analysis of yield performance. SAfr J Plant Soil. 2000;17(3):101107.

6. Crossa J, Gauch HG, Strobel RW. Additive mean effects and multiplicative interaction analysis of two international maize cultivar trails. Crop Sci. 1990;6(3):36-40.

7. Kempton RA. The use of biplots in interpreting variety by environment interactions. J Agric Sci. 1984;103(1):123-135.

8. Zobel RW, Wright MG, Gauch HG. Statistical analysis of yield trial. Agron J. 1988;80(3):388-393.

9. Campbell BT, Jones MA. Assessment of genotype $\mathrm{x}$ environment interactions for yield and fiber quality in cotton performance trials. Euphytica. 2005;144:69-78.

10. Mohammadi R, Amri A. Genotype x environment interaction for duram wheat grain yield and selection for drought tolerance in irrigated and drought environments in iran. J Crop Sci Biotech. 2011;14(4):265-274.

11. Fikere M, Tadesse T, Letta T. Cultivar-environment interactions and stability parameters for grain yield of Faba bean (Vacia faba L.) cultivars grown in South eastern Ethiopia. Int J Sustain Crop Prod. 2008;3:80-87.

12. Smith MF, Smith A. The success of the AMMI model in predicting Lucerne yields for cultivars with differing dormancy characteristics. $S$ Afr J Plant Soil. 1992;9(4):180-185.

13. Maali SH. Additive main effects and multiplicative interaction analysis of maize yield trials in South Africa. S Afr J Plant Soil. 2008;25:185-193.

14. Steyn PJ, Visser AF, Smith MF, et al. Ammi analysis of potato cultivar trials. S Afr Tydskri Plant Grond. 1993;10.

15. Sadeghi SM, Samizadeh H, Amiri E, et al. Additive main effects and multiplicative interactions (AMMI) analysis of dry leaf yield in tobacco hybrids across environments. African Journal of Biotechnology. 2011;10(21):4358-4364

16. Purchace JL. Parametric analysis to describe GX E interaction and yield stability in winter wheat. $\mathrm{PhD}$ Thesis. Department of Agronomy, Faculty of Agriculture, Bloemfontein, South Africa: University of the Orange Free State; 1997.

17. Geng S, Zhang Q, Bassett DM. Stability in yield and fiber quality of California Cotton. Crop Sci. 1987;27:1004-1010. 